\title{
EDITORIAL
}

\section{PESSOAS MIGRANTES E REFUGIADAS LGBTI}

\author{
LGBTI migrants and refugees
}

Roberto Marinucci*

O nexo entre mobilidade humana e orientação sexual/identidade de gênero ( $\mathrm{SOGl}$, na sigla em inglês) constitui um âmbito de pesquisa que pode elucidar tanto dinâmicas migratórias quanto percursos individuais e coletivos de construção identitária (Cantú, 2009). A literatura sobre migrações multiplicou nos últimos anos estudos referentes à diversidade étnica, racial, religiosa e geracional dos sujeitos envolvidos. De forma específica, aprofundou-se também a condição e as características peculiares da mulher migrante. No entanto, menos difundidos foram as investigações sobre como a identidade não heteronormativa pode incidir na decisão de migrar, na estruturação dos projetos migratórios, na incorporação nos países de chegada, principalmente no mercado de trabalho, e como, em outro sentido, o deslocamento geográfico pode interferir na formação e transformação da identidade de gênero.

Essas reflexões, na contemporaneidade, se inserem em um contexto paradoxal marcado por tendências antagônicas: avanços no reconhecimento dos direitos das minorias, e, ao mesmo tempo, fortes tendências de criminalização das migrações e das pessoas migrantes, sobretudo quando irregulares. Assim sendo, se por um lado cresce a pressão para que determinadas problemáticas relacionadas com a LGBTfobia sejam incluídas nos processos de elegibilidade dos pedidos de refúgio e, mais em geral, nas pautas da gestão migratória, por outro, as abordagens marcadamente securitárias e seletivas das políticas fronteiriças alimentam as restrições e, sobretudo, a desconfiança em relação a toda pessoa migrante, inclusive aquelas que solicitam refúgio por SOGl. As consequências são evidentes: diante dos oficiais de elegibilidade deve-se demonstrar não apenas a presença efetiva da perseguição e do risco de vida, mas provar também a própria orientação sexual e a identidade de gênero, com frequência mediante padrões de comportamento e sobretudo categorias de

Editor-chefe da Revista REMHU, Centro Scalabriniano de Estudos Migratórios (CSEM). Brasília DF, Brasil. E-mail: remhu@csem.org.br. Orcid: 0000-0002-2042-2628. 
autoidentificação estranhas ao universo cultural das pessoas envolvidas, além de ter que passar, às vezes, por perguntas ou até testes vexatórios.

Seja como for, a negação de direitos de pessoas LGBTI nos processos de elegibilidade é apenas a ponta do iceberg de um crescente aumento de violências nos países de origem e nas várias etapas do percurso migratório, inclusive no âmbito do tráfico de pessoas para fim de exploração sexual e outras formas de migração forçada. A gravidade dessa situação não diz respeito apenas à quantidade e à intensidade das violências, mas também à indiferença diante disso por parte de segmentos da sociedade e, não raramente, dos próprios Estados (UNHCR, 2010).

Cabe destacar, entretanto, que nem todos os deslocamentos de pessoas LGBTI são movidos por perseguições ou ameaças de vida. Muitas vezes, foge-se de um opressivo controle social em uma sociedade marcadamente patriarcal e heteronormativa, que acaba negando o direito de externalizar a própria identidade de gênero ou, inclusive, o direito à plena inclusão cidadã. A migração (o assim chamado "sexílio", exílio sexual), neste caso, se torna uma das possíveis estratégias de superação de adversidades, em busca da inclusão social em outro lugar. Uma forma de passing - em Goffman (2018, p. 97 [1963]), uma estratégia para dissimular o próprio "estigma", enquanto característica identitária considerada "desviante". O deslocamento geográfico, em outros termos, pode gerar uma "descontinuidade biográfica" (Goffman, 2018, p. 103) que permite reconstruir as próprias relações interpessoais em um novo meio ambiente social, possivelmente mais tolerante.

O êxito não é garantido. Na ótica do paradigma da interseccionalidade, determinadas problemáticas comuns nos processos das migrações discriminações, violências, isolamento, desemprego ou precarização do trabalho, entre outras - se tornam ainda mais severas no universo LGBTI, devido, possivelmente, à intersecção da LGBTfobia com outras fontes de discriminação (racismo, xenofobia, machismo, etnocentrismo), bem como à ausência ou precariedade de políticas públicas específicas nos países de chegada e, por vezes, à dificuldade de encontrar e contar com redes sociais de apoio (inclusive redes familiares).

A condição das pessoas migrantes e refugiadas LGBTI também apresenta novas questões relacionadas a temas que foram em boa medida exaustivamente pesquisados nos contextos migratórios, como por exemplo, o tema das remessas. Longe da própria terra, pessoas migrantes e refugiadas LGBTI, comumente, mantém relações transnacionais com os familiares. Às vezes, a família para a qual mandam remessas é a mesma família que os rejeitou e onde ocorreram casos de violência. No envio de remessas entram em jogo dinâmicas complexas de negociação e reconhecimento de afetos. Aqui se insere todo um âmbito de reflexão de cunho psicoantropológico sobre a saúde mental de pessoas 
marcadas por sofrimentos, discriminações e violências. Trata-se de um assunto que merece ser aprofundado em trabalhos acadêmicos com vistas à formulação de políticas públicas.

A questão da (in)visibilidade é também muito tratada: tornar-se visível (coming-out) permite fortalecer as lutas pelo reconhecimento, além de garantir o direito de externalizar a própria identidade; por outro lado, a invisibilidade pode se tornar uma necessidade a fim de evitar violências e outras formas de discriminação. A isso, deve-se acrescentar também que, em determinados casos, a linguagem do corpo não permite invisibilizar plenamente o "estigma" na acepção de Goffman - impedindo ou reduzindo a possibilidade de práticas de passing. Essa dialética entre visibilidade e invisibilidade assume ulteriores desafios em contextos migratórios, onde, como vimos, a LGBTfobia se intersecciona com outras fontes de discriminação, como etnia, nacionalidade ou fenotipia.

Vários artigos do Dossiê da REMHU, Revistas Interdisciplinar da Mobilidade Humana, n. 59, destacam também o que podemos chamar de lutas pelos direitos por parte de pessoas migrantes e refugiadas LGBTI. Às vezes, a ênfase nas violações tende a menosprezar o papel protagônico e disruptivo de indivíduos e coletivos LGBTI. A jornada de lutas da salvadorenha Karla Avelar, narrada e analisada no artigo de Amaral Arévalo, bem como a atuação de lideranças LGBTI venezuelanas no norte do Brasil sinalizada por Isadora Lins França e Arthur Fontgaland apontam para a transformação da brutalidade das violências recebidas em compromisso libertador de denúncia, articulação e construção de uma realidade social justa e solidária.

Finalmente, um aspecto não muito aprofundado nos artigos do Dossiê, mas sobre o qual gostaria de chamar atenção, é o papel das religiões: independentemente da interpretação que as diferentes doutrinas atribuem às relações homoafetivas, é papel imprescindível de todo grupo religioso prezar pelo respeito da dignidade e dos direitos de cada ser humano, no caso especifico não apenas no sentido de "não discriminar", mas também de apoiar ativamente as lutas pelo reconhecimento dos direitos das populações migrantes e refugiadas LGBTI. O que está em jogo, além do mais, é a credibilidade das mensagens fraternas e agápicas que a maioria dos sistemas religiosos veiculam. Nesta perspectiva, cabe destacar também sinais positivos, como o crescente compromisso institucional ou "de base" de algumas denominações religiosas, em termos de serviços assistenciais (Gutiérrez Albertos, 2017), apoio nas lutas por reconhecimento e, às vezes, na redefinição de visões doutrinais a respeito.

O Dossiê da REMHU inicia com o artigo de Fernanda Stang, que aborda o conceito de "fronteira", tanto na ótica migratória quanto naquela da subjetivização de gênero, questionando a violência que subjaz o carácter estático 
e rígido de determinadas definições e classificações (violência epistêmica). Analisando processos migratórios no Chile de pessoas colombianas e peruanas com subjetivizações sexo-genéricas não heteronormativas, a autora sublinha a heterogeneidade e multiplicidade das espacialidades e temporalidades das trajetórias das pessoas entrevistadas. Stang opta por uma interpretação da "fronteira" enquanto "interstício" espaço-temporal (estar entre), que não exclui dinâmicas de fechamento e passagem, mas frisa as "acciones corrosivas" das sedimentações culturais e conceituais, bem como possíveis processos criativos de autonomia.

A temática das fronteiras identitárias é aprofundada também por Giuseppe Masullo e Carmela Ferrara, que apresentam um estudo sobre o processo de autoidentificação de três mulheres com orientação sexual não heteronormativa, nascidas de coppie miste (um dos pais estrangeiro), na Itália. O artigo utiliza como chave epistêmica o paradigma interseccional a partir da contribuição de Gloria Anzaldúa, principalmente no que diz respeito aos conceitos de identidade mestiça (mestiza identity) e queer. No processo de autodeterminação identitária, as três mulheres de "fronteira" entrevistadas evitam assumir uma identificação estritamente binária, tanto em termos culturais quanto de orientação sexual. Esta leitura abrangente da autodeterminação identitária permite repensar os processos de autoidentificação no que diz respeito à identidade de gênero, assim como questionar a rigidez de determinadas categorias epistêmicas

Isadora Lins França e Arthur Fontgaland apresentam dois estudos etnográficos no norte do Brasil referentes a indivíduos venezuelanos LGBTI. Em termos gerais, as pesquisas chamam atenção para a precariedade da inserção laboral, as várias formas de violência e, inclusive, o caráter, por assim dizer, "experimental" das políticas de acolhimento nos abrigos. O artigo ressalta também a heterogeneidade e complexidade da categoria "população LGBTI", frequentemente acionada nas políticas de gestão de migrantes e refugiados, mas constantemente ressignificada e ampliada nas práticas dos sujeitos envolvidos. De fato, o acrônimo LGBTI (ou LGBTIQ+) antes que identificar um grupo homogêneo aponta para um conjunto diversificado de realidades que, longe de serem uniformizadas, exigem um olhar específico e, por vezes, individualizado, em termos de políticas públicas, sobretudo quando inseridas no mundo da mobilidade, onde se interseccionam e multiplicam numerosas variáveis identitárias (diferença de nacionalidade, etnia, idioma, religião, fenotipia) que podem levar a um acúmulo de efeitos discriminatórios e opressivos.

David Murray se debruça sobre o acolhimento de refugiados (SOGI) no Canadá, um país que de acordo com as narrativas oficiais se autocompreende como um lugar privilegiado na recepção de solicitantes de refúgio. $\mathrm{O}$ autor questiona essa visão um pouco idealizada mediante a análise do processo de determinação do status de refúgio. Entre outros aspectos, Murray atenta 
para a construção das narrativas dos requerentes, que precisam não apenas contar suas histórias, mas fazê-lo de acordo com os padrões epistêmicos e hermenêuticos dos oficiais de elegibilidade. Portanto, será necessário utilizar categorias ocidentais como "lésbica" ou "bissexual", incluir uma versão reificada da cultura homofóbica do país de origem e, ao mesmo tempo, provar sua identidade de gênero conforme padrões ocidentais. Há um "homonationalism" que orienta o processo.

Vítor Lopes Andrade, por sua vez, compara as políticas públicas no processo de reconhecimento do status de refúgio por SOGI adotadas no Reino Unido (um país do Norte do mundo) e na África do Sul (um país do Sul global). Apesar das peculiaridades de cada país, em ambos os casos o autor registra uma tendência em dificultar a obtenção do refúgio, uma certa "culture of disbelief", alegando falta de credibilidade dos solicitantes, questionando o fundado temor de perseguição (em nome do assim chamado critério da discrição) ou, mais simplesmente, multiplicando os entraves burocráticos. Portanto, mesmo dois países que possuem legislações por assim dizer "progressistas" em relação aos direitos da população LGBTI, de fato, obstaculizam o processo de elegibilidade.

O universo do lesbianismo é focado no artigo de Elena García-Oliveros, que apresenta o caso Marianna, mulher, senegalesa, lesbiana e racializada, que solicitou refúgio por motivos de gênero em Bruxelas. A autora destaca como, no processo de elegibilidade, os padrões frequentemente adotados são desdobramentos que se referem à homossexualidade masculina, o que torna mais difícil o reconhecimento das peculiaridades do lesbianismo. O estudo de caso de Marianna revela uma dessas peculiaridades: a assim chamada "violación correctiva", caracterizada, com frequência, pelo estupro, mas também, como no caso tratado pela autora, pela "mutilación genital femenina como forma de tortura con el agravante de persecución homofóbica". Apesar disso, a mutilação feminina é visibilizada e interpretada quase sempre como consequência da estrutura patriarcal, mas não como castigo ou correção do lesbianismo.

Sobre o tema da (in)visibilidade, numa ótica comunicacional, é enfocado o texto de Hadriel Theodoro, Denise Cogo e Amparo Huertas Bailén. A comunicação é interpretada na ótica da reprodução de subjetividades e identidades, o que envolve interações, disputas simbólicas e lutas pelo reconhecimento que, por sua vez, abrangem diferentes instâncias: "del cuerpo al lenguaje, de las identidades a las diferencias, del texto a la imagen, del sujeto a la colectividad". A partir dessas premissas, os autores/as destacam a temática da (in)visibilidade de forma dialética e a partir da dimensão subjetiva e coletiva: a invisibilidade pode ser uma fonte de opressão que subordina o ser humano a uma condição de inferioridade social, mas, em outros contextos, um refúgio diante da perseguição e da violência. Interpretar as lutas pela (in)visibilidade na 
ótica comunicacional abre novas perspectivas e desafios de ação, inclusive na ótica da autodeterminação dos sujeitos envolvidos.

O último artigo do Dossiê, de autoria de Amaral Arévalo, verte sobre a trajetória de Karla Avelar, mulher salvadorenha trans, vítima da violência das Maras, em El Salvador, obrigada a se refugiar no exterior após sofrer reiteradas formas de violência. $\mathrm{O}$ artigo ressalta vários aspectos: o ethos machista e homofóbico que envolve tanto as instituições civis, quanto os grupos criminosos (as Maras); as numerosas formas de violência legitimadas e incentivadas por esse ethos; a trajetória de vida de Karla Avelar e sua transformação de vítima a militante da causa dos direitos humanos, principalmente na ótica LGBTI. "La experiencia de vida de Karla Avelar", infere Arévalo, "apunta la necesidad institucional de reconocer las violencias específicas que las personas LGBTI+ padecen en sus países de origen, para realizar un análisis justo de sus pedidos de refugio".

$* * * *$

$\mathrm{Na}$ seção "Artigos" Nicholas De Genova analisa as migrações contemporâneas na ótica da "deportação" enquanto fator de vulnerabilização e exploração. De forma específica, o autor aprofunda a genealogia da deportação e evidencia como no passado minorias e grupos racializados, inclusive nacionais, foram objeto de deportação enquanto "estrangeiros virtuais ou de fato". Isso desmascara o papel desse dispositivo, que vai muito além da expulsão de "estrangeiros indesejáveis", pois visa promover a "descartabilidade definitiva e abjeta da vida humana". Finalmente, o autor atenta também para os sinais de autonomia por parte de migrantes deportados e suas práticas de remobilização: há vida e lutas após a deportação.

Ana Inés Mallimaci e María José Magliano focalizam a questáo das "esperas", da "falta de tempo" e suas implicações nas vidas de migrantes nas cidades de Buenos Aires e Córdoba, evidenciando como as populações estrangeiras possuem um amplo déficit temporal (devido à escassa possibilidade de agenciar seu próprio tempo), sobretudo no que diz respeito às mulheres em suas tarefas de cuidado e sua relação com o Estado. De fato, o acesso aos direitos sociais, distribuídos mediante a obtenção de determinados documentos - com suas temporalidades e esperas - parece atrelado à construção de um "sujeito paciente", o sujeito feminino. Conforme as autoras, "El tiempo de espera está desigualmente distribuido en nuestras sociedades y configura relaciones jerárquicas que subalternizan y regulan la vida de algunos colectivos, especialmente de los sectores populares, las mujeres y los/as migrantes".

Isac Alves Correia, Ricardo Ojima e Alisson Flávio Barbieri apresentam alguns resultados de uma pesquisa realizada na região do Seridó Potiguar, no 
nordeste brasileiro, com o objetivo de estudar as estratégias de adaptação da população em decorrência dos longos períodos de seca na região. No que diz respeito às migrações, os autores destacam os possíveis benefícios das remessas das pessoas migrantes, mas também os riscos e as vulnerabilidades que delas podem surgir. $\mathrm{O}$ artigo traz contribuições, inclusive, sobre os programas sociais e sua relação com o enfrentamento da seca e a decisão de migrar.

A construção da "fortaleza Europa" é objeto de estudo de Ana Belén Estrada Gorrín e María Cristina Fuentes Lara. A análise histórica destaca as várias etapas do processo que incluiu a abertura das fronteiras internas da União Europeia e, simultaneamente, um rigoroso fechamento daquelas externas, mediante a securitização e a externalização das fronteiras, bem como a hierarquização das pessoas a serem acolhidas - migrantes desejáveis e indesejáveis. As autoras, entre outros aspectos, chamam atenção também para a espetacularização do processo de controle e a utilização instrumental do discurso humanitário.

Sobre um tema análogo refletem também Minke Hajer e Maurizio Ambrosini num artigo que foca especificamente a ação de indivíduos, grupos a sociedade civil e ONGs em favor de migrantes irregulares, na cidade de Turim, na Itália, e Amsterdã, nos Países Baixos. Os autores se perguntam se essa ação humanitária, esse walfare from below, pode ser considerado um ato político e disruptivo ou meramente prático-assistencial e, de alguma forma, condizente com as políticas securitárias governamentais. Os autores inferem que em contextos de forte criminalização das pessoas migrantes e das migrações, mesmo ações práticas e emergenciais podem ter, direta ou indiretamente, conotações e efeitos políticos.

Na Seção Relatos e Reflexões, Patrícia Nabuco Martuscelli desenvolve uma reflexão na ótica das Relações Internacionais sobre a relação entre a soberania dos Estados e as migrações internacionais contemporâneas. A Resenha de Emanuela Bini do livro Migranti e rifugiate. Antropologia, genere e politica, di Barbara Pinelli encerra o número da Revista.

Desejamos a todas e todos uma boa leitura.

\section{Referências bibliográficas}

CANTÚ, Lionel Jr. The Sexuality of Migration: Border Crossings and Mexican Immigrant Men. New York: New York University Press, 2009.

GOFFMAN, Erving. Stigma. L'identità negata. Milano: Ombrecorte, 2018.

GUTIÉRREZ ALBERTOS, Víctor Hugo. La 72 como espacio intercultural de emancipación y resistencia trans en la frontera sur de México. Peninsula, v. XII, n, 2, p. 69-94, 2017.

UNHCR. The Protection of Lesbian, Gay, Bisexual, Transgender and Intersex Asylumseekers and refugees. Discussion Paper. 20.09.2010. 